\title{
Dexamethasone as an adjuvant to local anesthetic in ultrasound- guided thoracic wall block for breast cancer surgery. Report of 2 cases.
}

\author{
A. Ferrieri ${ }^{1}$, A. Marrone ${ }^{1}$, C. Bajocco ${ }^{2}$, M. D'Ettorre ${ }^{3}$, F. Petrini ${ }^{1}$, S.M. Maggiore ${ }^{1}$ \\ ${ }^{1}$ Department of Anesthesia, Intensive Care and Pain Medicine, G. d'Annunzio University, Chieti, Italy \\ ${ }^{2}$ Service of Anesthesia and Reanimation, ASST Gaetano Pino - CTO, Milano, Italy \\ ${ }^{3}$ Department of Anesthesia and Intensive Care, University Vita-Salute San Raffaele, Milano, Italy
}

\begin{abstract}
Background
Dexamethasone (DEX) is used as an adjuvant in regional anaesthesia, both in perineural and in fascicular blocks. Following an algic stimulus, DEX seems to attenuate C-fibers response, thus downregulating P-substance release and preventing neuropatic pain, and reduces cytokines release that sensitise the nociceptors. Its antiinflammatory properties ease the periaxonal inflammation and ischemia of the surgically traumatized nerve, thus sparing nerve fibers and decreasing further damage. However, DEX effect on the duration of analgesia and reduction in post-surgical pain is unclear, and no data exist on its use in patients undergoing regional anesthesia for breast surgery. We describe the effect of DEX on post-surgical pain in two patients undergoing regional anesthesia for breast surgery.
\end{abstract}

\section{Case report}

Two female patients (age: 60 years) underwent a supero-external segmentectomy with sentinel-node biopsy for breast cancer. The operation was performed with a thoracic wall block in deep sedation (Propofol $10 \mathrm{mg} / \mathrm{ml}$ injected at $2 \mathrm{mg} / \mathrm{kg} / \mathrm{h}$ ) with spontaneous respiration. All patients received an intravenous premedication (fentanyl 100 mcg plus midazolam $2 \mathrm{mg}$ ) and intraoperative paracetamol (1000 mg i.v.). Both patients received levobupivacaine $0.375 \%$ + lidocaine $0.5 \% 35 \mathrm{ml}$ for the thoracic wall block. Patient A received an intramuscular bolus of $8 \mathrm{mg}$ DEX. Patient B received $8 \mathrm{mg}$ fascicular DEX diluted in the local anesthetics. Pain was assessed with the numerical rating scale (NRS) up to $48 \mathrm{~h}$ after surgery. Adverse events were recorded.

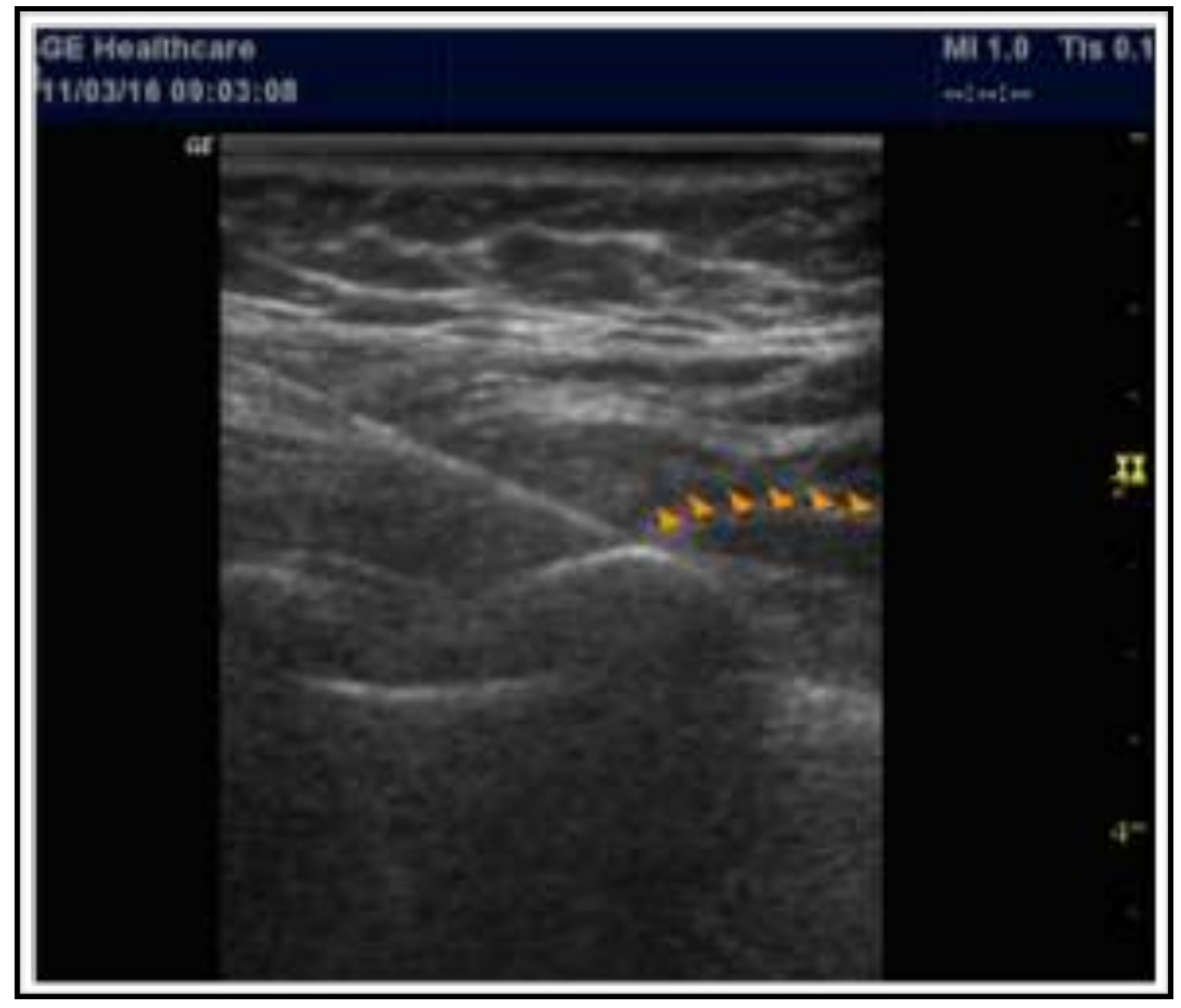

Pic. 1: Spread of local anesthetic above the 4th rib, below the serratus anterior muscle

\section{Discussion and results}

Both patients had no or very mild pain. In particular, patient A experienced mild pain (NRS=1) from 24 to 36 hours after the operation. Patient B experienced no pain in the first $48 \mathrm{hrs}$ after the operation. No adverse event was recorded.

\begin{tabular}{|c|c|c|c|c|c|c|c|c|}
\hline & $\begin{array}{c}\text { NRS } \\
2 \mathrm{~h}\end{array}$ & $\begin{array}{l}\text { NRS } \\
4 \mathrm{~h}\end{array}$ & $\begin{array}{c}\text { NRS } \\
6 \mathrm{~h}\end{array}$ & $\begin{array}{c}\text { NRS } \\
8 \mathrm{~h}\end{array}$ & $\begin{array}{l}\text { NRS } \\
12 \mathrm{~h}\end{array}$ & $\begin{array}{l}\text { NRS } \\
24 h\end{array}$ & $\begin{array}{c}\text { NRS } \\
36 \mathrm{~h}\end{array}$ & $\begin{array}{l}\text { NRS } \\
48 h\end{array}$ \\
\hline Patient A & 0 & 0 & 0 & 0 & 0 & 1 & 1 & 1 \\
\hline Patient B & 0 & 0 & 0 & 0 & 0 & 0 & 0 & 0 \\
\hline
\end{tabular}

\section{Learning points}

This report is one of the first on the use of adjuvant DEX for breast surgery regional anesthesia. In our patients, DEX administration (both i.m./fascicular) during thoracic wall block for breast cancer surgery was feasible and safe, and could have played a role in decreasing or delaying postoperative pain. 